\section{Agricultural innovation and inclusive value-chain development: a review}

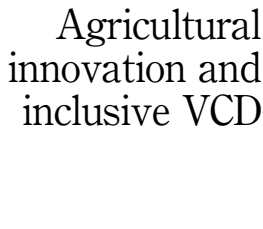

99

Andre Devaux

Latin America Regional Office, International Potato Center, Lima, Peru

Maximo Torero

World Bank, Washington, District of Columbia, USA

Jason Donovan

International Centre for Research in AgroForestry, Lima, Peru, and

Douglas Horton
Received 21 June 2017 Revised 17 July 2017 Accepted 17 July 2017

\begin{abstract}
Purpose - The purpose of this paper is twofold: first, to take stock of the current state of knowledge about inclusive value-chain development (VCD) in the context of international agricultural research; and second, to draw out the implications for future research and action.

Design/methodology/approach - This paper is based on a review of recent research papers authored by professionals affiliated with international agricultural research centers and their partners in Africa, Asia, and Latin America.

Findings - The studies reviewed in the paper identify the opportunities emerging from new and expanding markets for agricultural products and challenges to smallholder participation in these markets. It identifies key attributes of successful value-chain interventions, emphasizing the importance of combining value-chain approaches with other approaches, including those emerging from innovation systems and rural livelihoods frameworks. Methods are offered for evaluating complex value-chain interventions.

Research limitations/implications - The paper summarizes the state of knowledge as of early 2016 in a dynamic field. Important contributions to knowledge may have been made since then.

Originality/value - The paper summarizes the state of knowledge in the field, and identifies emerging issues and policy implications, knowledge gaps, and priorities for future applied research.

Keywords Evaluation, Food security, Agricultural research, Inclusive development,

Multistakeholder platform, Scaling up, Smallholders

Paper type Literature review
\end{abstract}

\section{Introduction and background}

For agricultural research to benefit the rural poor, it needs to complement other efforts that improve the policy environment, alleviate resource constraints, and build local capacity for responding to changing technological and economic challenges and opportunities. Action may also be needed to influence the incentives and constraints faced by large-scale retailers

(C) Andre Devaux, Maximo Torero, Jason Donovan and Douglas Horton. Published by Emerald Publishing Limited. This article is published under the Creative Commons Attribution (CC BY 4.0) licence. Anyone may reproduce, distribute, translate and create derivative works of this article (for both commercial and non-commercial purposes), subject to full attribution to the original publication and authors. The full terms of this licence may be seen at http://creativecommons.org/ licences/by/4.0/legalcode

The authors thank the members of the Research Program on Policies, Institutions, and Markets of the Consultative Group on International Agricultural Research (CGIAR) - and particularly the members of the Program's Value Chain Flagship - for supporting the preparation of this paper. This research was supported by the CGIAR fund donors. 
JADEE 8,1

and buyers, for them to more effectively engage with smallholder producers and build mutually beneficial business relationships that are able to stand the test of time.

It is widely believed that together, such efforts can lead to tangible improvements in smallholders' production and marketing practices, benefitting smallholders as well as other market participants. However, there are relatively few documented cases of interventions that have been successful in promoting inclusive value-chain development (VCD).

Since the 1970s, international agricultural research centers have worked with national and regional partners to stimulate agricultural innovation and growth. In many cases, the benefits derived by smallholders have been constrained by these farmers' limited opportunities to market their products. In an attempt to expand the benefits of agricultural research and development (R\&D) for smallholders, since 2000, many organizations have experimented with approaches for promoting innovation on small farms and inclusive VCD.

Traditionally, different groups based in different organizations have designed and implemented interventions that focused on production and marketing. While agricultural research organizations have focused on increasing agricultural production and productivity, non-governmental organizations (NGOs) and others concerned with agribusiness development have focused on marketing and VCD. The overall impact of interventions in these two areas has been limited in part by the lack of a more holistic approach that addresses challenges and opportunities all along the value chain, from input suppliers and farmers' fields, through the various stages in the market chain, all the way up to the ultimate consumers. Evaluation has also been commonly identified as an area that requires strengthening in complex interventions, such as those that promote inclusive innovation and VCD.

In 2013, the Research Program on Policies, Institutions, and Markets in the Consultative Group on International Agricultural Research (CGIAR) decided to take stock of the state of knowledge on inclusive agricultural VCD in the context of international agricultural research[1]. Researchers from throughout the CGIAR were invited to submit papers on innovation for inclusive VCD. More than 30 submissions were received and reviewed for their relevance to current debates on how agricultural research, innovation, and VCD can benefit smallholders, and for their scientific quality. After the initial review, 14 papers were selected for more in-depth review and inclusion in a book (Devaux et al., 2016)[2].

This paper presents highlights of the research papers reviewed, and identifies the main themes that emerge from this research, the policy implications, and priorities for future research. Section 2 introduces key concepts and perspectives related to research, innovation, and VCD. Section 3 presents highlights of the papers reviewed. Section 4 discusses the main themes that emerge from the research review and the policy implications, and Section 5 identifies important gaps in the research reviewed, and priorities for future work to promote innovation and inclusive VCD.

\section{Perspectives on agricultural research, innovation, and VCD}

Views on the role of agricultural research, innovation, and VCD in reducing rural poverty, and on their interrelationships, have evolved substantially in recent years. This section introduces key concepts and clarifies their meaning in the context of this review.

\subsection{Perspectives on agricultural research and innovation}

Agricultural research has often been confused with innovation. However, there are important differences between them. Research is concerned with the production of new knowledge, which may or may not be used in practice. Innovation, on the other hand, is concerned with the processes of change in the production and marketing of goods and services - changes that may or may not be driven by research. 
In the context of agricultural development, innovation has been defined as "the process by which individuals or organizations master and implement the design and production of goods and services that are new to them, irrespective of whether they are new to their competitors, their country, or the world" (World Bank, 2012, p. 2).

When CGIAR was established in the early 1970s, its strategy was "to use the best science in advanced countries to develop technologies for the benefit of food-deficit countries and populations" (Lele, 2004, p. 3). At that time, agricultural research was assumed to be the principal source of farm-level innovation, which would increase productivity, benefitting poor farmers as well as consumers. In essence, the research results were assumed to flow through an "innovation pipeline" from basic research conducted by advanced research institutes, to strategic research conducted by CGIAR centers, to applied and adaptive research conducted by regional and national programs, and finally through outreach or extension programs to farmer adopters (Biggs, 1990; Ashby, 2009).

Over time, the limits of the pipeline model became apparent as our understanding of innovation processes improved, more actors became involved in research and innovation processes, and stakeholders began to expect agricultural research to solve more complex problems of rural poverty, food insecurity, nutrition, and sustainable management of natural resources. As a result, after the 1970s, priorities shifted from building agricultural research institutes to strengthening research systems, improving technology transfer, linking researchers more effectively with farmers, strengthening agricultural innovation systems, and developing value inclusive chains (Pant and Hambly, 2009; Donovan et al., 2015).

Innovation is stimulated by the interaction of individuals and organizations with diverse - often conflicting - stakes in the management of scarce resources or the governance of productive processes. For this reason, interventions to promote innovation often involve what may be called "innovation brokering" or "facilitation," which focuses on enabling other actors to engage in critical reflection, experimentation, and joint learning (Klerkx et al., 2009, p. 413).

The institutional arrangements and standard operating procedures of agricultural R\&D organizations have tended to lag behind the evolution of thinking on innovation processes and systems (Hall, 2009, p. 30). Consequently, most agricultural research organizations continue top focus on expanding the supply of new technologies rather than on linking research more effectively to change processes on farms and in value chains.

Despite the continuing dominance of the pipeline model of innovation, some donors have supported project teams within agricultural research organizations that have been charged with making better use of research to benefit the poor. These teams, generally focused on specific countries or regions, have experimented with new ways to link research with development and strengthen the contributions of research to agricultural innovation and small farmers' welfare. Many of these teams have achieved promising results. But few have documented their approaches and the results in peer-reviewed publications, limiting their contributions to knowledge and practice on linking research with development.

\subsection{Perspectives on VCD}

Value-chain concepts represent an important change in thinking about development and the relationships among agricultural producers, traders, processors, and consumers. The term "value chain" is used in different ways in the professional literatures. In this paper, a value chain refers to the sequence of interlinked agents and markets that transforms inputs and services into products with attributes that consumers are prepared to purchase. Millions of low-income people, a large proportion of whom are women, participate in agricultural value chains as producers, traders, processors, and retailers. 
JADEE 8,1

Many millions more, including most of the developing world's poor, participate in agricultural value chains as laborers or consumers. As Raj (2011) argues, in this journal's inaugural editorial:

Agriculture "can play a significant role in the livelihoods of rural populations by providing work opportunities related to agribusiness. Indeed, agribusinesses at any scale, even micro-enterprises, begin to provide a path to economic well-being."

Haggblade et al. (2010, p. 1429) note:

[...] landless and near-landless households everywhere depend heavily on non-farm income for their survival, while agricultural households count on non-farm earnings to diversify risk, moderate seasonal income swings, and finance agricultural input purchases.

Therefore, improving the performance of agricultural value chains stands to benefit large numbers of people (Reardon and Timmer, 2012; Reardon et al., 2012; Aramyan et al., 2005; Lohman et al., 2004; Lambert and Pohlen, 2001; Tschirley et al., 2015).

Agro processing is a key component of the rural non-farm economy. Most studies of VCD associate "modern" enterprises with "large-scale" ones, which are highly visible in and around cities in the processing and retail sectors - employing large numbers of workers and serving large numbers of (mainly urban) consumers. In contrast, most of the studies reviewed in the present paper highlight modernization processes that are taking place among small and medium-sized agro-enterprises located in rural areas and small towns. These enterprises often face the double challenge of responding to effectively to the evolving demands of processors and consumers, as well as supporting their smallholder input suppliers in upgrading their capacity to deliver quality inputs in sufficient volumes.

VCD refers to a type of intervention that aims to address poverty through improved linkages between businesses and poor households within a value chain. In contrast to the traditional agricultural R\&D approaches that focus narrowly on improving the capacities of smallholders to increase their productivity or better manage natural resources, VCD challenges $R \& D$ organizations to work with diverse stakeholders to understand the performance of the value chain and identify mutually beneficial options for improving chain performance. It is reasoned that by working in closer collaboration with private sector actors, VCD can increase the benefits for the poor and enhance the prospects for sustaining operations and benefits after the termination of an intervention. For smallholders, benefits may include increased income, more secure market linkages, and access to new services for production. For wholesalers, processors, and other downstream enterprises, benefits may include improved quality and flow of raw material, reduced transaction costs, and enhanced environmental and social credentials.

VCD often targets marginalized actors in a value chain, such as smallholders, small-scale businesses, and landless laborers. Such "inclusive" VCD has been defined as a "positive or desirable change in a value chain to extend or improve productive operations and generate social benefits: poverty reduction, income and employment generation, economic growth, environmental performance, gender equity and other development goals" (UNIDO, 2011, p. 1). It is from this perspective that many development agencies, donors, and governments have adopted VCD as a key element of their rural poverty-reduction strategies (Humphrey and Navas-Alemán, 2010).

There is a reason for both optimism and concern regarding the poverty-reduction potential of VCD. While globalizing markets offer opportunities for marketing higher-value products that simply did not exist before, these markets generally demand considerably more in terms of business acumen, efficiency, and attention to quality and food safety standards than markets for traditional products (Reardon et al., 2009). Value-chain participation in more demanding markets requires smallholders to deliver 
regular supplies of produce of consistent quality and sufficient quantity. Meeting these conditions requires access to land, inputs, technology, knowledge, organization, capacity, skill, and infrastructure, which may not exist in some communities or among some groups of asset-poor producers.

The limited asset endowment of an individual farm family is not the only thing that may limit the benefits it derives from market participation. Participation of smallholder farmers in high-value markets exposes them to new risks, which might outweigh the potential benefits (Ricketts et al., 2014). An analysis of experiences in Latin America (Berdegue et al., 2015) indicates that the marketing opportunities and performance of family farmers are strongly influenced by the local economic environment, or "proximate context." Smallholders who operate in areas experiencing open, dynamic development - for example, near provincial towns with growing incomes, markets, and employment - tend to have more market opportunities and take better advantage of them than farmers in less economically dynamic areas.

There is an urgent need to learn from experiences with VCD interventions, in order to improve the design of future interventions. This reflects both the inherent complexity of designing and implementing interventions with small businesses and the rural poor, and the growing pressures for development programs to achieve more impact in less time and with fewer resources.

\section{Overview of recent research}

A central purpose of the present paper is to take stock of the current state of knowledge on ways to foster agricultural innovation and inclusive VCD. Many of the papers reviewed cover a range of topics. But they can usefully be grouped under three headings, depending on their main contributions to the state of knowledge:

(1) those which provide insights on challenges to inclusive VCD and approaches for promoting it;

(2) those which provide lessons for linking innovation and VCD; and

(3) those which examine methods for evaluating innovation and VCD.

Table I provides summary information on these three sets of papers.

\subsection{Challenges and approaches for inclusive VCD}

Four of the papers reviewed focus mainly on the approaches used by the private sector and development agencies for bringing smallholders into value chains for higher value agricultural products, and the related challenges faced. Donovan et al. (2015) provides a comparative review of tools available for designing VCD interventions. It reviews 11 guides for value-chain analysis - a first step in the design of VCD strategies. The guides provide a useful framework for understanding markets and engaging with value-chain stakeholders. However, the guides often overlook a critical issue for achieving inclusive VCD: the basic conditions necessary for VCD to advance development objectives and achieve sustainability. The authors suggest three areas for future critical reflection and debate on the design of guides for VCD:

(1) concepts, methods, and tools for addressing the specific challenges and needs of the poor in value chains;

(2) tools for identifying important factors in the context of value chains and the implications for interventions; and

(3) mechanisms for mutual learning on the design and implementation of VCD interventions. 
$\underset{8,1}{\text { JADEE }}$

104

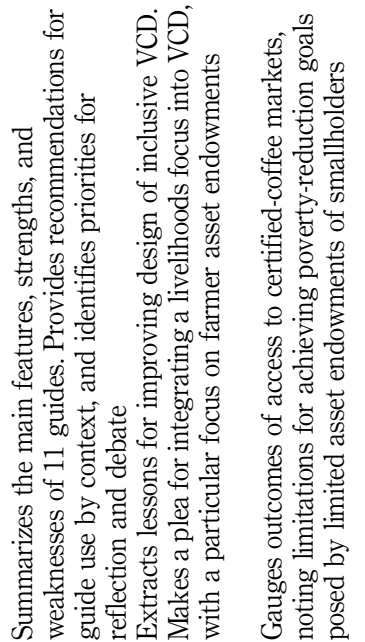

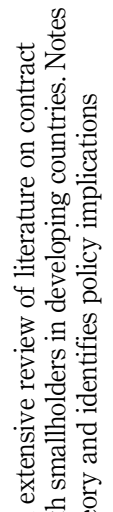

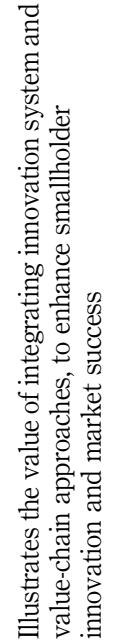

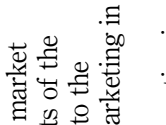

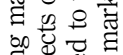

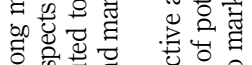

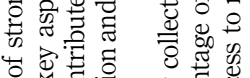

可记

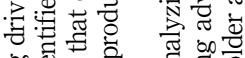

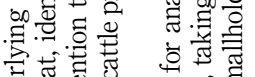

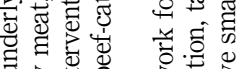

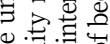

要

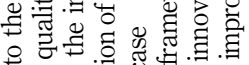

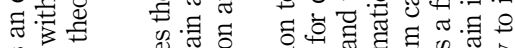

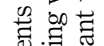

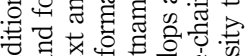

焉这

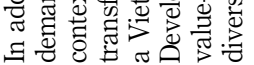
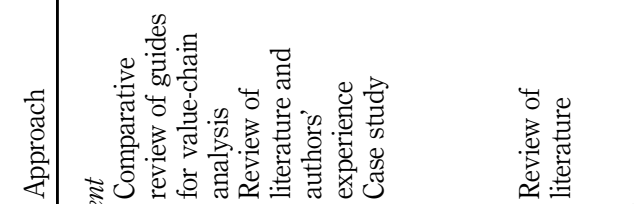

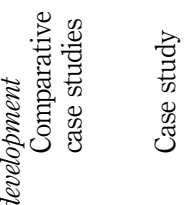

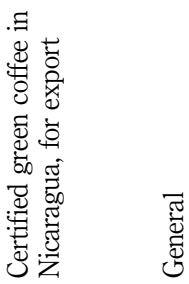

胥.

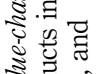

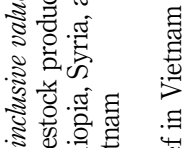

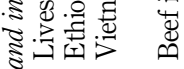

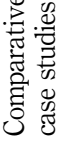

空

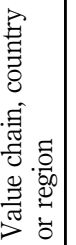

Table I.

Summary information on the papers reviewed

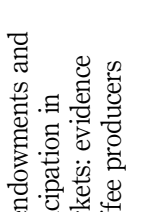

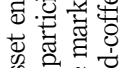

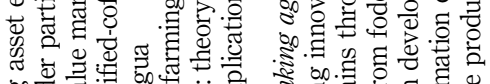

:

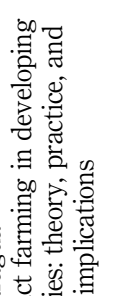

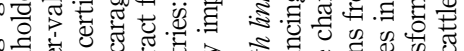

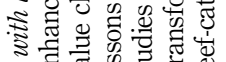

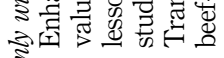

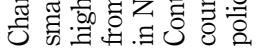

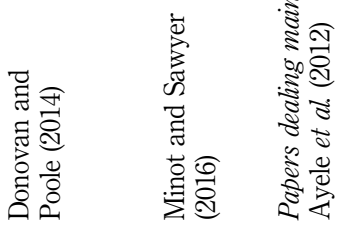

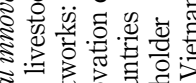

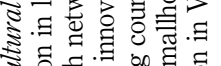

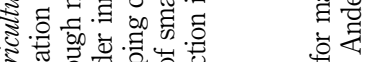

के के

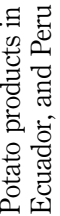

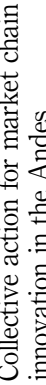

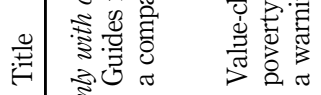

ส্ৰ

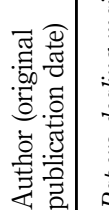

इ

:

$\widetilde{8}$

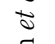

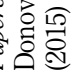

善 


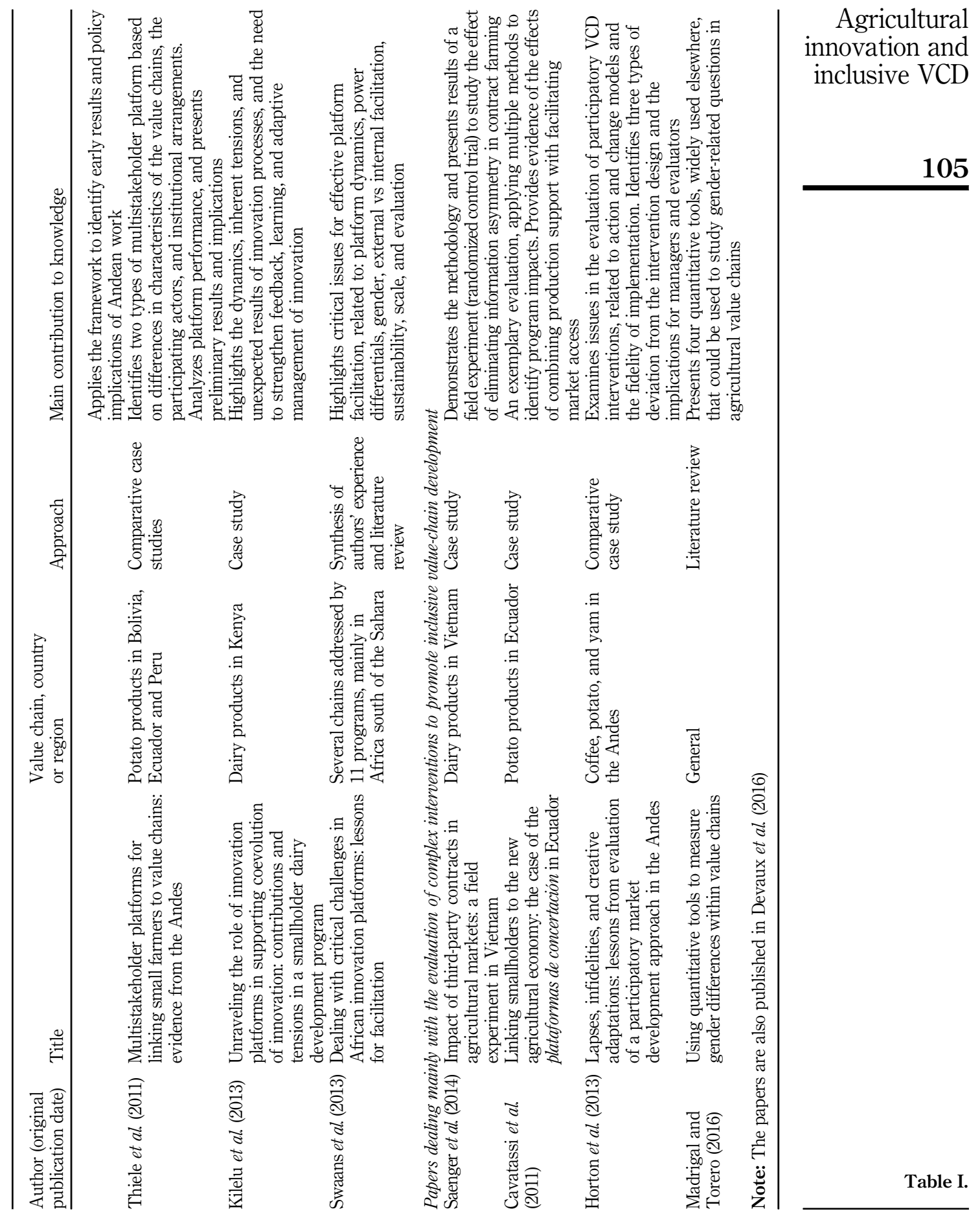


JADEE 8,1
Stoian et al. (2012) present a strong case for why those who aim to advance inclusive VCD need to better consider the needs and circumstances of the rural poor. They emphasize the bottlenecks, trade-offs, and dilemmas that can arise when attempting to link poor farming households with higher-value markets. Drawing on their own experiences in working with NGOs and the private sector, and an overview of recent experiences with VCD, the authors' plea for a deeper focus on the needs and circumstances of local actors. The design of VCD interventions often assumes that poor households: have sufficient resources to effectively participate in VCD, do not face substantial trade-offs when using these resources, and are able to assume higher risks when reinvesting capital and labor. However, these assumptions seldom reflect the circumstances of the rural poor. The authors encourage donor agencies and development practitioners to adopt asset-based approaches to the design, implementation, and assessment of value chains, and to identify the non-market interventions needed for enabling disenfranchised groups to meet the minimum asset thresholds for their successful participation in value-chain initiatives.

Donovan and Poole (2014) analyze changing asset endowments and smallholder participation in Nicaragua's certified-coffee market, in the context of interventions that aimed to ameliorate the negative impacts of a "coffee crisis." The authors' analysis suggests that most small-scale coffee farmers built particular elements of their asset base and increased their resilience to future shocks through access to value chains for certified coffee. However, households struggled to make effective use of the gains to improve their livelihoods. Few of the least-endowed households increased the scale or productivity of coffee, and most continued to depend heavily on subsistence production and seasonal off-farm income. The authors conclude that improved market access alone, even under relatively favorable market conditions and with considerable external support, may have uncertain impacts on rural poverty if the underlying constraints on household assets and investments are not addressed concurrently.

Contract farming is one way to address market failures by integrating smallholders into modern agricultural value chains, providing them with inputs, technical assistance, and market access. However, the imbalance of power between farmers and the companies that organize and manage contract-farming schemes may put small farmers at a distinct disadvantage in such arrangements. Minot and Sawyer (2016) review the theory and practice of contract farming in developing countries and their policy implications. Most empirical studies suggest that contract-farming schemes raise the incomes of participating farmers by 25-75 percent. The evidence is less clear on the degree to which buyers are willing to contract smallholders and on the extent of benefits for small holders, who generally have much less power than contractors. In some cases, contractors accept or even prefer working with smallholders, but they face challenges in enforcing quality standards when small farmers lack access to credit, technology, inputs, and infrastructure. Nevertheless, contract farming cannot serve as a broad strategy for rural development because it is economically justifiable mainly for certain high-value commodities in certain markets. In those circumstances, however, it can be an effective institution for helping smallholders raise productivity and access more remunerative markets.

\subsection{Linking agricultural innovation and VCD}

The practical application of innovation system and VCD approaches - and particularly the integration of these two approaches - is challenging, and there are few well-documented cases of their successful application. Six of the papers reviewed show how agricultural researchers and development professionals in national and regional organizations associated with CGIAR programs have grappled with fundamental issues of linking 
research with action, how they interpreted and applied innovation system and VCD thinking, and the results that have been obtained in Asia, Latin America, and Africa south of the Sahara.

Fodder scarcity is a perennial problem for many smallholders in developing countries. Ayele et al. (2012) present lessons from fodder innovation studies in Ethiopia, Syria, and Vietnam. Fodder innovation is triggered and diffused by the actors interacting and learning in networks, and on farms. Fodder innovation, being only one element of livestock value chains, is sustainably enhanced when linked to other innovations and market-oriented activities that optimize productivity gains. Yet smallholders face systemic constraints to accessing markets, and a need to organize in groups to exploit opportunities. The authors conclude that rather than treating innovation system and value-chain approaches as separate tools, the integration of their complementary features enhances smallholders' innovation and market success.

Stür et al. (2013) analyze the transformation of smallholder beef-cattle production in rural Ea Kar, Vietnam, where smallholder crop-livestock farmers were able to take advantage of the rising demand for meat in urban centers and transform cattle production from a traditional, extensive grazing system to a more intensive, stall-fed system that supplies quality meat to urban markets. Introduction and expansion of farm-grown fodder production enabled farmers to produce fatter animals, achieve higher sale prices, and reduce labor inputs by moving from grazing to stall feeding. These benefits convinced farmers, traders, and local government that smallholder cattle production could be a viable enterprise. Within ten years, the way that cattle were produced and marketed changed significantly in the area. In addition to the underlying driver of strong market demand for quality meat, several of the key factors contributed to this transition:

- a convincing innovation that provided immediate benefits to farmers and provided a vision for local stakeholders;

- a participatory, systems-oriented innovation process that emphasized capacity strengthening;

- a value-chain approach that linked farmers and local traders to markets;

- formation of a loosely structured coalition of local stakeholders that facilitated and managed the innovation process; and

- technical support over a sufficiently long period to allow innovation processes to become sustainable.

Devaux et al. (2009) present the case of the Papa Andina network in the Andes which used collective action in two approaches for fostering market chain innovation: the participatory market chain approach and stakeholder platforms. Both approaches bring small-scale potato producers together with market agents and agricultural service providers to identify common interests, share market knowledge, and develop new business opportunities. These forms of collective action help to overcome market failures by strengthening linkages among smallholders, service providers (including researchers), and market agents. The facilitated interactions have stimulated innovation and helped to create new market niches for native potatoes grown by poor farmers in remote highland areas. The authors describe Papa Andina's experiences with innovation in value chains and discuss the policy implications for R\&D organizations and the need for R\&D organizations to have the capacity to diagnose innovation systems and facilitate group processes involving people with diverse stakes in a commodity's production, marketing, and use.

Thiele et al. (2011) focus on multistakeholder platforms for linking smallholders to value chains in Bolivia, Ecuador, and Peru. Although value chains linked to urban markets and
Agricultural innovation and inclusive VCD 
JADEE 8,1 agro-industry present new opportunities for adding value and raising rural incomes, smallholders struggle to enter these markets, and a lack of trust among value-chain actors increases transaction costs and short-circuits innovation. Differences in characteristics of value chains, participating actors, and institutional arrangements have led to the emergence of two types of platforms. One type brings traders, processors, supermarkets, and others together with farmer associations and R\&D organizations to foster commercial, institutional, and technological innovation. The other type is structured around geographically delimited supply areas, meshing farmers, and service providers to address market governance issues in assuring volumes, meeting quality, and timeliness constraints, and empowering farmers. The cases studied indicate that platforms that bring stakeholders together around value chains can result in new products, processes, norms, and behaviors that could not have been achieved otherwise and that benefit poor farmers.

The agricultural innovation system approach emphasizes the collective nature of innovation and stresses that innovation is a co-evolutionary process. These insights are increasingly informing interventions that focus on setting up multistakeholder initiatives, such as innovation platforms and networks to enhance agricultural innovation. Several recent studies have addressed the issues of platform organization, but there has been limited analysis of how platforms shape innovation processes. Kilelu et al. (2013) attempt to unravel the role of innovation platforms in supporting innovation through an in-depth case study of a smallholder dairy development program in Kenya. The findings indicate that highly dynamic innovation processes produce interactional tensions and unexpected effects, and that intermediation and facilitation are crucial for resolving tensions that emerge at different actor interfaces. It is also noted that platforms are not always able to adapt adequately to emerging issues. This points to the need to look at platforms dynamically and pay more attention to mechanisms that strengthen feedback, learning, and adaptive management in innovation processes.

Innovation platforms are increasingly used by $R \& D$ initiatives to engage the poor in agricultural innovation processes. These platforms are forums for action and learning, in which different types of actors come together to address the issues of mutual concern. The dynamic nature of the innovation process and the differences in interest, capacity, and power among the actors involved make facilitation of innovation platforms challenging. Based on the group reflection on their own personal experiences facilitating innovation platforms, Swaans et al. (2013) analyze seven key issues that were found to be critical to effective platform facilitation:

(1) the dynamic and evolving nature of platforms;

(2) power dynamics;

(3) gender equity;

(4) external vs internal facilitation;

(5) sustainability of the process;

(6) issues of scale; and

(7) monitoring and evaluation.

\subsection{Evaluating interventions for innovation and VCD}

Evaluation seeks to accumulate credible knowledge of what works and what does not work. The overarching goal is to improve the effectiveness of development projects in reducing global poverty, by generating information that will help to:

- improve the design of projects based on experience; 
- improve accountability, by clearly identifying the causal links from intervention to impact;

- identify successful projects to be scaled up; and innovation and
inclusive VCD

- improve the allocation of resources across programs by better understanding what works well, and how and which interventions are more cost-effective than others.

It is not feasible to conduct rigorous impact evaluations for all interventions, because of the complexity of the interventions, the variation of contexts in which they are implemented, and the difficulty of gauging results with and without the intervention. Some examples of the types of value-chain intervention for which impact evaluation would be especially useful are:

- innovative schemes to upgrade value chains;

- pilot programs that are due to be substantially scaled up;

- interventions for which there is scant solid evidence of impact in the given context; and

- when there is a clear need to prioritize projects based on cost-effectiveness.

Four papers address the issues related to the evaluation of complex interventions aimed at inclusive VCD, including, for example, trade-offs between ensuring the fidelity of the intervention and promoting local adaptation of intervention protocols, identification of programs' economic impacts, use of experimental evaluation approaches, and quantitative tools for measuring gender differences within value chains.

Using a randomized field experiment in Vietnam, Saenger et al. (2014) examine the effect of alleviating the information asymmetry regarding product quality that is widespread in contracts between agricultural producers and buyers in developing countries. In contract farming, opportunistic buyers may underreport quality levels to farmers to reduce the price that they have to pay. In response, farmers may curb investment, thereby negatively affecting farm productivity. In the experiment, the authors entitled randomly selected smallholder dairy farmers in Vietnam, who are contracted by a large company, to independently verify milk-testing results. The results indicate that treatment farmers used 12 percent more inputs, and they also significantly increased their output. Some wider research and policy implications are discussed.

Cavatassi et al. (2011) present an economic analysis of the use of multistakeholder platforms (plataformas de concertación) to link smallholders to high-value food markets by looking at the experience of a platform program in the Ecuadorian highlands. Multiple evaluation methods are used to ensure identification of program impact. The findings suggest that the program successfully improved the welfare of beneficiary farmers, as measured by yields and gross margins. These benefits were achieved through improving the efficiency of agricultural production and selling at higher prices. No significant health or environmental effects were found. Overall, the program provides clear evidence that combining production support with facilitating market access can be successful.

Participatory approaches are frequently recommended for international development programs, but few have been evaluated. To contribute to the knowledge on the use and results of participatory methods, from 2007 to 2010 the Andean Change Alliance evaluated the participatory market chain approach. Horton et al. (2013) examine the fidelity of implementation, the factors that influenced implementation and results, and the approach's change model in four cases in Bolivia, Colombia, and Peru. The authors identify three types of deviation from the intervention protocol - lapses, creative adaptations, and true infidelities - and discuss the implications for intervention design 
JADEE 8,1

\section{0}

and implementation. They also identify five groups of variables that influenced the implementation and results of the approach:

(1) attributes of the macro context;

(2) attributes of the market chain;

(3) attributes of the key actors involved;

(4) local rules in use; and

(5) the intervention's capacity development strategy.

Although there was insufficient information to test the validity of the change model, results were greatest where the approach was implemented with highest fidelity. The case analysis suggests that the single most critical component of the approach is the engagement of market agents - in addition to farmers - throughout the intervention. Lessons for planning and evaluating participatory approaches are presented, in relation to the use of action and change models, the importance of monitoring implementation fidelity, the limits of baseline survey data for outcome evaluation, and the importance of capacity development for implementers.

Madrigal and Torero (2016) explore the use of quantitative tools to measure gender differences within value chains, and argue that using quantitative tools to study gender-related questions in a value-chain context can encourage gender inclusion and promote economic growth in developing countries. Four tools are proposed, based on widely known methods in gender and labor economics literature that have straightforward empirical implementation. These tools - which have been tested and proven useful for gender analysis in other settings - could help researchers identify critical issues and value-chain bottlenecks in order to pinpoint more effective and inclusive policies and development strategies.

\section{Emerging themes and policy implications}

The papers reviewed deal with many aspects of agricultural innovation and VCD in different geographic, social, economic, and institutional contexts. From this broad range of experiences, six common themes emerge, which relate to:

(1) opportunities created by the expansion of markets for agricultural products;

(2) challenges for smallholders and the policy implications;

(3) complex nature of agricultural innovation and VCD processes;

(4) challenges for interventions that promote inclusive VCD;

(5) attributes of successful interventions;

(6) the centrality of institutional innovation; and

(7) the role of multistakeholder platforms in VCD.

\subsection{Opportunities created by the expansion of markets for agricultural products}

The reviewed papers reinforce the view that access to lucrative markets for agricultural products can benefit smallholders in developing countries, and that interventions that address technical, economic, and institutional challenges can help smallholders take advantage of these opportunities. Nevertheless, VCD is not a panacea that alone can solve rural poverty problems. In many cases, inclusive VCD interventions that support small-scale and rural enterprises will have little impact unless they are complemented with policy 
changes that create a more conducive environment for enterprise development and help smallholders gain a foothold in lucrative value chains.

In recent years, the policy and agribusiness environments of most countries have become more open, liberal, and dynamic. There has been a rapid growth in urban demand for high-value foodstuffs in both developing countries and foreign markets. Niche markets in advanced urban economies continue to generate strong demand, especially for organic and fair-trade items.

Smallholders can supply markets with diverse food products (Hazell and Rahman, 2014) and they may have a comparative advantage in producing high-value, labor-intensive products, such as perishable fruits, vegetables, and specialty crops. Farmers in remote areas often have a deep knowledge of neglected and underutilized species, such as quinoa, amaranth, and native potatoes in the Andes, for which lucrative new markets are being developed (Giuliani et al., 2012). Improvements in transportation are reducing marketing costs, and information technology is helping reduce the asymmetries in market information that have traditionally put rural smallholders at a disadvantage vis-à-vis large farmers and market agents (Webb, 2013).

\subsection{Challenges for smallholders}

Smallholders often find it difficult to exploit the opportunities presented by expanding markets. Concerns over the scarcity of agricultural raw materials in rapidly growing markets, coupled with more stringent food safety and quality standards enforced by government agencies and supermarkets, have spurred market integration and increased coordination and collaboration among producers, processors, and retailers (Dolan and Humphrey, 2000; Reardon and Timmer, 2012). But smallholders are often excluded from these increasingly complex and dynamic markets.

Smallholders often have limited access to land, credit, technical advice, basic knowledge of the market system, and current information on market prices and conditions - all of which restrict their capacity to invest, expand their market surplus, and add value to their produce. The limited market surpluses of individual smallholders raise the unit cost of assembling, handling, and transporting their products.

These common attributes of smallholders highlight the importance of policies and programs that strengthen farmer associations and collective marketing. The experiences reviewed indicate that poor households require minimum assets to successfully participate in VCD. Women are especially disadvantaged when it comes to access to land, labor, credit, and infrastructure. The implication is that gender issues need to be considered specifically in the design, implementation, and evaluation of interventions.

\subsection{Complexity of agricultural innovation and VCD}

Agricultural innovation and VCD processes are highly complex. Numerous factors and variables are interacting in these processes, and there are many unknowns. Consequently, there is no single recipe for success of interventions and their outcomes are largely unpredictable. Complexity has important implications for the design and implementation of interventions, which are discussed in the following section[3].

Different types of intervention, and innovation, often reinforce each other. For example, separate interventions that focus on improving the productivity of dairy cattle, on milk marketing, on credit, on farmer organization, or on policies may produce some benefits for smallholders on their own. But when combined, they may produce much more substantial and long-lasting benefits. This point is illustrated by the experiences with dairy development in Kenya and Vietnam reported on by Kilelu et al. (2013) and Stür et al. (2013). The implication is that those who design and implement applied R\&D programs should
Agricultural innovation and inclusive VCD 
JADEE 8,1

112 seek to combine efforts that promote agricultural innovation and VCD, rather than work in isolation.

The benefits of agricultural innovation and market development are unequally distributed. It has long been understood that early adopters stand to gain more from innovation processes than late adopters. The cases reviewed indicate that the distribution of benefits in VCD depends in part on the initial asset endowment of participating farmers. Lower and upper asset thresholds are crucial for the distribution of benefits. Below a lower threshold, smallholders may have insufficient resources to participate in dynamic value chains and may be negatively impacted by VCD interventions. Between the lower and upper thresholds, the participants may benefit significantly from the intervention. Above the upper threshold, participants may benefit little from the interventions, since they were already participating actively in markets and deriving significant benefits prior to the intervention.

The livelihood strategies and asset endowments of an individual farming households are not, of course, the only aspects that determine the benefits derived from market participation. Based on a regional study in Latin America, Berdegue et al. (2015) concluded that the benefits that farming households reap from engagement in agricultural markets were strongly influenced by the local economic environment. Recent trends in the international markets for coffee, cocoa, oil palm, and other crops have shown the major implications that sustained fluctuations in prices can have on the livelihoods of farming households.

Approaches to promote innovation and VCD should consider smallholders' livelihood strategies and asset endowments, as well as the local economic context. They should apply asset-based approaches to identify the non-market interventions needed to enable the poorest groups to meet minimum asset thresholds to participate successfully in VCD initiatives, or transition out of agriculture. It is especially important to pay attention to the needs and opportunities of women and other marginalized groups, who may benefit from, or be adversely affected by, innovation and VCD. To achieve gender inclusion, gender imbalances need to be identified and appropriate interventions or components designed.

\subsection{Challenges for achieving inclusive VCD}

Interventions that have stimulated innovation processes that produced substantial benefits for smallholders have had to overcome numerous challenges. One set of challenges in public sector agricultural research organizations relates to the limited availability of work vehicles, fuel, and per diems needed for work off station. Additionally, public research organizations are often hesitant to work with large private firms or NGOs. Researchers may also be wary of "getting bogged down in development work" or discouraged from doing it because of the traditional research mandate of their organization. To cope with these challenges, international organizations have often taken the lead in facilitating innovation and VCD processes, and they have provided essential resources for off-station work. In some cases, they have enlisted the collaboration of NGOs to play leadership roles. Local ownership of, and responsibility for, interventions has been cultivated via the development of coalitions or platforms, discussed in a separate section below.

A second set of challenges concerns the involvement of large private firms. Creativity is positively associated with the diversity of stakeholders involved in innovation processes. In many cases, large marketing or processing firms could play important roles in the innovation processes. But it has been difficult to encourage these firms to invest the time needed in what they often feel are unproductive meetings that produce few immediate results for them. For this reason, there has been a tendency for platforms to work initially with small entrepreneurs, and bring larger businesses on board once they can see the potential value of early innovations. 
The lack of well-trained local facilitators or innovation brokers has been another common challenge, and this is an important reason why international organizations have often - at least initially - led the process of facilitating innovation, and then prioritized capacity strengthening for local facilitators (Donovan et al., 2017). The development of methodological guides and capacity building has been among the most important contributions of international organizations to local innovation capacity. It is important to note, however, that it has been easier to strengthen the capacity of individuals than to bring about changes in their parent organizations to take full advantage of their newly developed innovation and inclusive VCD capacities. This point is discussed more fully in Section 4.6, on institutional innovation.

A final challenge has been to overcome donor demands for quick results. R\&D organizations are under increasing pressure from donors to produce quicker results with more limited resources (Pingali, 2010; McCalla, 2014). Interventions that have generated significant benefits have generally been carried out over a decade or more, with support from international donors and a stable organizational environment (often provided by an international organization). The policy implication is that donors that wish to generate significant returns on investments in inclusive VCD should plan to provide external support for several years - probably at least a decade.

\subsection{Attributes of successful interventions}

In the context of this review, a successful intervention is one that generates significant and potentially lasting benefits for the rural poor at scale. As noted at several points, few rigorous evaluations of VCD interventions exist, limiting the extent to which we can draw firm conclusions based on experiences to date. Nevertheless, supports the following general propositions, which hopefully will be tested in future applied research and evaluation studies:

- Interventions that focus narrowly on either expanding production or developing value chains have limited benefits for the poor.

- Interventions that combine agricultural innovation and VCD have synergistic effects.

- Multistakeholder platforms that foster commercial, technical, and institutional innovation have more significant and lasting impacts than those focused on governance and coordination issues.

- Inclusivity is an elusive ideal. Effective participation in VCD requires a minimum set of assets (not only land and financial capital, but also knowledge, skills, social capital, and access to sources of technical support), which the poorest of the poor lack. So, while successful interventions broaden participation in VCD, benefitting the poor, they should not be expected to produce significant direct benefits for the poorest of the poor.

- The main benefits of VCD for the poorest rural groups - those with very small parcels or no land at all - may come from expanded employment in production, processing, and marketing activities and in reduced prices of agricultural products.

- There is no single recipe for inclusive VCD. Interventions need to be tailored to fit the opportunities and constraints of particular places and targeted to reach specific groups.

- Learning and change are crucial for success. Since innovation and VCD processes are inherently unpredictable, intervention strategies and priorities need to evolve over time. Program managers need to be supported by effective monitoring systems, so they can learn from successes and failures, and they need the administrative 
JADEE 8,1

114 flexibility to be able to respond effectively to the challenges and opportunities as they emerge.

- Project-based interventions are not enough. VCD interventions have been most successful where the economic and policy environments have supported rural enterprise development and where appropriate policy changes accompanied the interventions.

- Time is essential for results to emerge. The most successful cases benefitted from continuous support - from donors, international organizations, and national partners - over a decade or more. Follow-up studies show that the benefits of VCD interventions often continue to emerge years after the interventions terminate, through successive waves of innovation and change (Mayanja et al., 2012; Devaux et al., 2013).

Until recently, interventions have tended to focus either on agricultural research and farm-level innovation or on VCD. However, frustrations with traditional interventions, particularly with those focused on increasing production, have led to the development of more integrated interventions involving both agricultural innovation and VCD. Examples of successful integrated interventions include the International Livestock Research Institute's, work with the Smallholder Dairy Development Project in Kenya (Kilelu et al., 2013), their work with fodder innovation and beef production in Vietnam (Stür et al., 2013), and the International Potato Center's (CIP), work with the participatory market chain approach (Devaux et al, 2013). Several other CGIAR centers and partner organizations have also implemented initiatives that have attempted to combine both agricultural innovation and VCD approaches. But to date, few of these cases have been analyzed in peer-reviewed publications.

Interventions that combined innovation systems and $\mathrm{VCD}$ approaches generally began with technical research, which was later complemented with participatory approaches involving farmers, and later yet addressed issues of market access and VCD. They were flexible and adapted to needs and opportunities as they emerged. As the scope of work broadened from conducting research to facilitating innovation and then embraced VCD, the number and diversity of stakeholders increased and coalition building and facilitation became more important.

Based on their work with local Vietnamese researchers, development professionals, government officials, farmers, market agents, and others, over more than a decade, Stür et al. (2013) have identified the following components of an emergent strategy:

- a convincing technical innovation;

- a participatory, systems-oriented innovation process;

- a VCD approach that links farmers and local traders to growing markets;

- formation of loosely structured coalitions of local stakeholders; and

- provision of technical support over an extended period of time - perhaps a decade or more.

CIP's work with participatory market chain approach in South America also began with technical research. Early on, researchers incorporated participatory approaches to engage farmers in applied R\&D. Later they began to work with other service providers and groups of market chain actors to develop new products. Early marketing efforts stimulated innovation in both institutional arrangements and production technology - for example, contracts between farmer groups and processors, and use of new varieties and postharvest methods. 
Existing institutional arrangements with buyers often limit the ability of smallholders and small market agents to increase their benefits from value-chain participation. Smallholders often distrust local buyers, resulting in increased their transaction costs and reduced incentives for farmers to invest in yield-increasing technologies. Product quality is increasingly important for determining farmers' pay in high-value markets, and costly technology is needed to assess invisible quality attributes, such as nutrient content and pesticide residues. In this context, weak institutions for ensuring the fair measurement of product quality and for enforcing contracts can negatively impact smallholders.

Institutional innovations - such as multistakeholder platforms, farmer organizations, contract-farming arrangements, independent bodies for product quality verification, and new R\&D approaches - have played key roles in inclusive VCD. Multistakeholder platforms will be discussed in the following section. Several of the studies reviewed show how farmer organizations have aided in reducing transaction costs in input and product markets, by improving product assembly and quality assurance, and by organizing supplies of inputs, credit, and technical assistance. Farmer organizations have also aided in negotiating more favorable contract terms and conditions for smallholders. It is important to note, however, that farmer organizations often require some sort of long-term external support (Berdegué, 2001).

The absence of effective standards and certification systems and the weakness of broader legal systems often limit the development of markets for high-quality produce (see, e.g. Bhattarai et al., 2013; Zylberberg, 2013; Narine et al., 2015).

Contract farming can help farmers overcome market failures by linking them with output markets for high-value foods and guaranteeing them a market for their produce. However, contract farming on its own may be insufficient to improve the income of smallholder households (Mwambi et al., 2016). When contractors provide inputs, credit, or technical advice, contract farming can also help farmers to access technology and input markets. Contract farming can raise the incomes of participating farmers. But its application is limited to high-value crops and livestock products that are sold on quality-sensitive markets. Where market institutions are weak, independent bodies for product quality verification can improve contract enforcement, benefitting both buyers and sellers.

Strengthening local institutional arrangements (e.g. to enforce contracts and provide independent verification of product quality in contract-farming schemes) can contribute significantly to the development of agricultural markets and the benefits reaped by smallholders. Innovations in contract design are important to balance the power between smallholders and the monopsonistic power of contracting companies. One example is the third-party certification proposed by Saenger et al. (2014). Other innovations are mentioned by Minot and Sawyer (2016) and Shanoyan et al. (2014).

Innovations in R\&D approaches are an important way to foster innovation processes in the productive sector, benefitting smallholders and other economic actors. Several chapters show how the participation of research organizations in multistakeholder platforms and acting as innovation brokers has improved the linkages between researchers and other service providers and value-chain actors. This has contributed both to innovations in the productive sector and to improving the focus of applied research on the challenges and opportunities identified by value chain actors.

As a cautionary note, it is important to realize that institutions - be they market institutions or the rules and procedures of agricultural R\&D organizations - are often highly resistant to change. This is one reason why many promising innovation system and VCD approaches developed by externally funded project teams have not been mainstreamed in the parent R\&D organizations. 

$\underset{8,1}{\text { JADEE }}$

\subsection{Role of multistakeholder platforms in VCD}

Many of the cases studied have involved multistakeholder platforms that engaged individuals with different - often conflicting - stakes in a common resource or process in social learning, trust building, and collective action. Some platforms have fostered market chain innovation, others have sought to improve chain governance and coordination, and yet others have promoted both innovation and improvement of market chain governance.

Effective facilitation, or innovation brokerage, is crucial for the success of multistakeholder platforms, and involves network formation, coordination, technical backstopping, mediation of disputes, advocacy, capacity building, and documentation of results. In recent years, many NGOs have developed their capacity for facilitating events, and some have further developed their capacities for innovation brokerage. Essential knowledge, attitudes, and skills for brokering innovation processes remain scarce in most agricultural research organizations, highlighting the need for investments in capacity development, if agricultural research organizations are to play useful roles in facilitating the work of platforms (Horton, 2012; Yusuf and Trondsen, 2014). Professionals based at a number of international and national R\&D organizations have recently prepared a set of guidelines for designing, budgeting, and implementing successful innovation platforms (Schut et al., 2017).

Since innovation and VCD are complex processes, multistakeholder platforms need to be flexibly managed, learn from experience, and adapt to unfolding events. Several of the platforms analyzed played different roles at different times and their structures evolved accordingly.

Mechanisms for platform funding, planning, management, and governance need to allow for continual adaptation to emerging challenges and opportunities. Platform managers need the support of learning-oriented monitoring and evaluation. They also need evidence of impacts to justify platform funding. Since platforms facilitate processes, but do not themselves produce tangible results, it is difficult to demonstrate their value through impact studies. Developing the capacities needed for learning, documentation, and impact assessment remains a challenge for many platforms.

Platforms can have various degrees of formality and longevity. Some have written charters and official government recognition, but most have less formal structures and operate through more informal interactions among actors for specific purposes. Where platforms are concerned with natural resources management, their longevity is crucial for achieving sustainable results. But transitory development coalitions can play useful roles in promoting innovation and inclusive VCD.

The studies reviewed illustrate how socioeconomic, institutional, ecological, and technical conditions vary widely over time and space, and consequently, interventions that promote inclusive VCD need to be tailored to fit specific local conditions and evolve in response to changing conditions, opportunities, and threats. The policy implication is that while general principles of agricultural innovation and VCD are broadly applicable, rigid models for innovation platforms cannot simply be scaled up or transferred from one place to another.

The need for flexible arrangements and quick responses can make it difficult for public sector R\&D organizations to participate effectively in platforms. For this reason, organizational reforms may be needed in many agricultural research organizations to be able to play effective roles in promoting innovation and inclusive $\operatorname{VCD}[4]$.

\section{Priorities for future research}

This review suggests a number of priorities for future research, which fall under five broad headings. 
5.1 Methods for implementing asset-based approaches to VCD

There is a broad consensus that the asset endowments of smallholders and other market chain actors shape their ability to participate in and benefit from VCD. Important issues related to asset endowments that shape the capacity of resource-poor actors to participate in value chains include livelihood and business strategies, access to financial, technical, and business-related services for building asset endowments over time, and the overall business environment in which these actors operate.

Where access to productive assets is limited, actors are less likely to investment in activities linked to a given value chain, either because they lack a capacity to do so or would face major trade-offs to shift assets toward relatively risky and uncertain market-related activities.

VC interventions typically have targeted only some of the underlying constraints to market participation by resource-poor actors. Practical methods are needed for more holistic assessments of asset endowments that would better inform the planning and implementation of $\mathrm{VC}$ interventions.

There is urgent need for deeper learning from experiences to design $\mathrm{VC}$ interventions, to respond more effectively to the needs and circumstances of resource-poor actors. Methods are needed for managing the inherent complexity of VCD with small businesses and the rural poor, the wide variety of conditions under which $\mathrm{VC}$ interventions are implemented, and contemporary pressures faced by development agencies to achieve greater outcomes under pressing time and budget constraints.

In particular, methods are needed for determining the "value-chain readiness" of the potential participants and capturing gender differences along the value chain. More practical methods are also needed for incorporating learning-oriented monitoring and evaluation into VCD interventions.

\subsection{Membership, management, and facilitation of multistakeholder platforms}

Comparative assessment of experiences with different types of platform, management systems, and facilitation arrangements is needed to clarify how such things as member diversity, the formality of management structures and systems, and different facilitation arrangements influence platform performance in different contexts. More systematic evaluation is also needed to assess the impacts of innovation platforms and their cost-effectiveness relative to other types of innovation brokerage and mechanisms for improving market governance. Since the present review was conducted, Dror et al. (2016) have published several experiences with innovation platforms for agricultural development, and Schut et al. (2017) have published guidelines on how to design, budget, and implement innovation platforms. These publications have added valuable information on some of the knowledge gaps concerning innovation platforms, which have been identified in the present paper.

\subsection{Evaluation approaches}

Applied research and evaluation are needed to draw lessons from experience and test the (often implicit) assumptions and the action and change models that guide value chain interventions. Interventions for inclusive VCD present evaluators with numerous challenges. Most of the studies reviewed highlight the need to improve evaluation and learning among private sector stakeholders, development agencies, and researchers, in order to support adaptive management, to provide information on cost-effectiveness, to strengthen accountability for the resources used, and to answer more fundamental questions related to the value and benefits of inclusive VCD, vis-à-vis alternative approaches for improving the lot of the rural poor. It is also important to reduce the burden and cost of evaluations and to identify practical methods for assessing changes along the value chain. Different approaches
Agricultural innovation and inclusive VCD 
JADEE 8,1

to learning are needed, ranging from structured learning approaches within the context of a particular VC (with the aim to identify bottlenecks and adjust actions), to more externally led evaluations (for impact assessment and to satisfy accountability requirements). Perhaps the most important potential value of evaluation is to provide businesses and development agencies with context-specific guidance on how to design, implement, and monitoring programs for advancing inclusive VCD - what might works, what is not likely to work, and what safeguards and alternative planning scenarios might be available.

Research is needed to find the ways to capture heterogeneity and achieve greater impact at scale - that is, to understand how much the results achieved can be extrapolated to other areas or even other value chains of similar commodities. In most impact evaluations, it is assumed that the estimated treatment effects can be generalized to broader populations in different locations. However, since both the individuals and the locations may have different characteristics, the impacts may vary significantly across locations. Several authors have questioned policy recommendations that they believe are based on the implicit extrapolation from a small number of trials to a wide variety of dissimilar contexts (Deaton, 2010; Pritchett and Sandefur, 2013). A growing body of empirical research shows that identical policies have different effects among individuals with the same observed characteristics living in different contexts, because of unobserved differences between populations. Hence, methods are needed that account for heterogeneity across locations, or we need to design evaluations that take this issue into account from the beginning to be able to assure that a successful intervention can be scaled up and we can clearly identify in advance the potential magnitude of its impact.

A number of the articles reviewed rely less on experimental evaluation approaches and more on participatory and collaborative ones. There is active exploration of such methods in the fields of program evaluation and sustainability science (Patton, 2008, 2011; Cash et al., 2003; Clark et al., 2016). Applied research is needed to ascertain the utility of these and other related methods in the realm of inclusive VCD, to generate information that decision makers consider salient, legitimate, and credible, and actually utilize to inform their decisions.

\subsection{Scaling up the impact of value chain interventions}

Following on the discussion in Section 5.3, most of the documented experiences with inclusive VCD have been at the level of pilot projects. Many questions remain concerning the feasibility of expanding and extending these pilots to achieve greater impact; and how best to scale up promising approaches while taking into consideration the heterogeneity of conditions in which VCD takes place.

VC approaches cannot be simply "scaled up" or "transferred" to other settings. However they may be usefully adapted and applied elsewhere, if attention is paid to the local context. As an example, the participatory market chain approach was developed to respond to a set of problems with a specific crop in a specific region. However, through capacity-building efforts, the approach has also been applied with other crops facing other challenges and opportunities in other countries. The approach was not simply "transferred" from one place to another. In each case, capacity development was a priority, and local professionals developed the ability to adapt the approach to fit local circumstances and needs. The approach has contributed most to development where it has been employed as one part of a broader set of interventions that have included research, strengthening multi-sectorial platforms, policy influence, and public awareness (Ordinola et al., 2014).

Partnering is generally believed to be crucial for upscaling, and different types of partnership may be needed for achieving large-scale impacts. Applied research and evaluation are needed to synthesize lessons for upscaling VCD, and for assessing the extent to which lessons learned in other fields of development could be usefully applied for scaling up the results of inclusive $\mathrm{VCD}[5]$. 


\subsection{Application of a gender lens}

Women participate in many activities along value chains, and value chain may have differential impacts on women and men. More applied research and systematic evaluation is needed to offer donors, researchers, and development professionals with practical and effective methods and tools for designing and implementing intervention strategies that enhance the benefits realized by women who participate in value chains. Some experiences have been documented and offer recommendations for mainstreaming gender in agricultural innovation processes (Polar et al., 2015) and in value-chain interventions (Mayanja et al., 2016). These should be reviewed with an eye to developing more inclusive agricultural innovation and VCD processes. Deeper insights into the opportunities to improve women's' benefits from VCD may provide guidance on how to better incorporate youth, ethnic minorities, and other underrepresented groups in VCD. In addition, it will be important to look at gender across the value chain and identify if there is gender exclusion, wage gaps, or segmentation (where some part of the chain (e.g. household processing) is dominated by females). Knowing such things is needed to increase empowerment of women, which goes beyond improving women's access to markets and ensures that women have opportunities to earn more income and accumulate more assets.

\section{Notes}

1. The CGIAR is a network of research centers established in the 1970 s to mobilize modern science to expand the production of basic foods in developing countries. The network, which currently includes 15 research centers, has the mission of working to advance agricultural science and innovation to enable poor people, especially women, to better nourish their families, and improve productivity and resilience so they can share in economic growth and manage natural resources in the face of climate change and other challenges (www.cgiar.org/our-strategy).

2. The book is available at the eLibrary of the International Food Policy Research Institute, available at: http://ebrary.ifpri.org/cdm/ref/collection/p15738coll2/id/130788

3. For general discussions of the implications of complexity for design, implementation, and evaluation of interventions, see Patton (2011) and Bamberger et al. (2016).

4. Horton (2012) discusses the types of organizational changes that may be needed.

5. For example, reviews of experiences with scaling up at the International Fund for Agricultural Development and the United Nations Development Program have drawn potentially useful lessons (Hartman et al., 2013; Begovic et al., 2017).

\section{References}

Aramyan, L., Lansink, A. and van Kooten, O. (2005), "Testing a performance measurement framework for agri-food supply chains (abstract)", Developing Entrepreneurship Abilities to Feed the World in a Sustainable Way, 15th International Farm Management Conference, São Paulo, August 14-29.

Ashby, J. (2009), "Fostering farmer first methodological innovation: organizational learning and change in international agricultural research", in Scoones, I. and Thompson, J. (Eds), Farmer First Revisited: Innovation for Agricultural Research and Development, Practical Action Publishing, Rugby, pp. 39-45.

Ayele, S., Duncan, A., Larbi, A. and Tan Khanh, T. (2012), "Enhancing innovation in livestock value chains through networks: lessons from fodder innovation case studies in developing countries", Science \& Public Policy, Vol. 39 No. 3, pp. 333-346.

Bamberger, M., Vaessen, J. and Raimondo, E. (Eds) (2016), Dealing with Complexity in Development Evaluation: A Practical Approach, Sage, Los Angeles, CA. 
JADEE 8,1

Begovic, M., Linn, J. and Vrbensky, R. (2017), "Scaling up the impact of development interventions: lessons from a review of UNDP country programs", Global Economy \& Development Working Paper No. 101, The Brookings Institute, Washington, DC.

Berdegué, J. (2001), "Cooperating to compete: associative peasant business firms in Chile", doctoral thesis, Wageningen Agricultural University, Wageningen.

Berdegue, J.A., Bebbington, A. and Escobal, A. (2015), "Conceptualizing spatial diversity in Latin American rural development: structures, institutions, and coalitions", World Development, Vol. 73, September, pp. 1-10.

Bhattarai, S., Lyne, M. and Martin, S. (2013), "Assessing the performance of a supply chain for organic vegetables from a smallholder perspective", Journal of Agribusiness in Developing and Emerging Economies, Vol. 3 No. 2, pp. 101-118.

Biggs, S. (1990), "A multiple source of innovation model of agricultural research and technology promotion”, World Development, Vol. 18 No. 11, pp. 1481-1490.

Cash, D., Clark, W., Alcock, F., Dickson, N., Eckley, N., Guston, D., Jager, J. and Mitchell, R. (2003), "Knowledge systems for sustainable development", Proceedings of the National Academy of Sciences of the USA, Vol. 100 No. 14, pp. 8086-8091.

Cavatassi, R., González-Flores, M., Winters, P., Andrade-Piedra, J., Espinosa, P. and Thiele, G. (2011), "Linking smallholders to the new agricultural economy: the case of the plataformas de concertación in Ecuador", Journal of Development Studies, Vol. 47 No. 10, pp. 1545-1573.

Clark, W., Kerkhoff, L., Lebel, L. and Gallopin, G. (2016), "Crafting usable knowledge for sustainable development", Proceedings of the National Academy of Sciences of the USA, Vol. 113 No. 17, pp. $4570-4578$.

Deaton, A. (2010), "Instruments, randomization, and learning about development", Journal of Economic Literature, Vol. 48 No. 2, pp. 424-455.

Devaux, A., Horton, D., Velasco, C., Thiele, G., López, G., Bernet, T., Reinoso, I. and Ordinola, M. (2009), "Collective action for market chain innovation in the Andes", Food Policy, Vol. 34 No. 1, pp. 31-38.

Devaux, A., Ordinola, M., Mayanja, S., Campilan, D. and Horton, D. (2013), "The participatory market chain approach: from the Andes to Africa and Asia”, Papa Andina Innovation Brief No. 1, International Potato Center, Lima.

Devaux, A., Torero, M., Donovan, J. and Horton, D. (Eds) (2016), Innovation for Inclusive Value Chain Development: Successes and Challenges, International Food Policy Research Institute, Washington, DC.

Dolan, C. and Humphrey, J. (2000), "Governance and trade in fresh vegetables: impact of UK supermarkets on horticulture industry", Journal of Development Studies, Vol. 37 No. 2, pp. 147-176.

Donovan, J. and Poole, N. (2014), "Changing asset endowments and smallholder participation in higher value markets: evidence from certified coffee producers in Nicaragua", Food Policy, Vol. 44, pp. 1-13.

Donovan, J., Stoian, D. and Poe, K. (2017), "Value chain development in Nicaragua: prevailing approaches and tools and persistent gaps", Enterprise Development and Microfinance, Vol. 28 Nos 1/2, pp. 10-27.

Donovan, J., Franzel, S., Cunhja, M., Gyau, A. and Mithofer, D. (2015), "Guides for value chain development: a comparative review", Journal of Agribusiness in Developing and Emerging Economies, Vol. 5 No. 1, pp. 2-23.

Dror, I., Cadilhon, J., Schut, M., Misiko, M. and Maheshwari, S. (2016), Innovation Platforms for Agricultural Development: Evaluating the Mature Innovation Platforms Landscape, Rutledge, London and New York, NY.

Giuliani, A., Hintermann, F., Rojas, W. and Padulosi, S. (Eds) (2012), Biodiversity of Andean Grains: Balancing Market Potential and Sustainable Livelihoods, Bioversity International, Rome.

Haggblade, S., Hazell, P. and Reardon, T. (2010), "The rural non-farm economy: prospects for growth and poverty reduction”, World Development, Vol. 38 No. 10, pp. 1429-1441. 
Hall, A. (2009), "Challenges to strengthening agricultural innovation systems: where do we go from here?", in Scoones, I. and Thompson, J. (Eds), Farmer First Revisited: Innovation for Agricultural Research and Development, Practical Action Publishing, Rugby, pp. 30-38.

Hartmann, A., Kharas, H., Kohl, R., Linn, J., Massler, B. and Sourang, C. (2013), "Scaling up programs for the rural poor: IFAD's experience, lessons and prospects (Phase 2)", Global Economy and Development Working Paper No. 54, The Brookings Institute, Washington, DC.

Hazell, P. and Rahman, A. (Eds) (2014), New Directions for Smallholder Agriculture, Oxford University Press, Oxford.

Horton, D. (2012), "Organizational change for learning and innovation", Agricultural Innovation Systems: An Investment Sourcebook, World Bank, Washington, DC, pp. 316-325.

Horton, D., Rotondo, E., Paz Ybarnegaray, R., Hareau, G., Devaux, A. and Thiele, G. (2013), "Lapses, infidelities, and creative adaptations: lessons from evaluation of a participatory market development approach in the Andes", Evaluation \& Program Planning, Vol. 39, August, pp. 28-41.

Humphrey, J. and Navas-Alemán, L. (2010), "Value chains, donor interventions and poverty reduction: a review of donor practice", IDS Research Report No. 63, Institute of Development Studies, Brighton.

Kilelu, C., Klerkx, L. and Leeuwis, C. (2013), "Unraveling the role of innovation platforms in supporting co-evolution of innovation: contributions and tensions in a smallholder dairy development programme", Agricultural Systems, Vol. 118, June, pp. 65-77.

Klerkx, L., Hall, A. and Leeuwis, C. (2009), "Strengthening agricultural innovation capacity: are innovation brokers the answer?", International Journal of Agricultural Resources, Governance and Ecology, Vol. 8 Nos. 5/6, pp. 409-438.

Lambert, D. and Pohlen, T. (2001), "Supply chain metrics", International Journal of Logistics Management, Vol. 12 No. 1, pp. 1-19.

Lele, U. (2004), The CGIAR at 31: An Independent Meta-Evaluation of the Consultative Group on International Agricultural Research, World Bank, Washington, DC.

Lohman, C., Fortuin, L. and Wouters, M. (2004), "Designing a performance measurement system: a case study", European Journal of Operational Research, Vol. 15 No. 6, pp. 267-286.

McCalla, A. (2014), "CGIAR reform - why so difficult?", Working Paper No. 14-001, Department of Agricultural and Resource Economics, University of California at Davis, Davis CA.

Madrigal, L. and Torero, M. (2016), "Using quantitative tools to measure gender differences within value chains", in Devaux, A., Torero, M., Donovan, J. and Horton, D. (Eds), Innovation for Inclusive Value Chain Development: Successes and Challenges, International Food Policy Research Institute, Washington, DC, pp. 441-464.

Mayanja, S., Akello, B., Horton, D., Kisauzi, D. and Magala, D. (2012), "Value chain development in Uganda: lessons from the participatory market chain approach", Banwa, Vol. 9 Nos 1/2, pp. 64-96.

Mayanja, S., Barone, S., McEwan, M., Thomas, B., Amaya, N., Terrillon, J., Velasco, C., Babini, C., Thiele, G., Prain, G. and Devaux, A. (2016), Prototype Guide for Integrating Gender into Participatory Market Chain Approach, International Potato Center, Lima.

Minot, N. and Sawyer, B. (2016), "Contract farming in developing countries: theory, practice, and policy implications", in Devaux, A., Torero, M., Horton, D. and Donovan, J. (Eds), Innovation for Inclusive Value Chain Development: Successes and Challenges, International Food Policy Research Institute, Washington, DC, pp. 127-155.

Mwambi, M., Oduol, J., Msehga, P. and Saidi, M. (2016), "Does contract farming improve smallholder income? The case of avocado farmers in Kenya", Journal of Agribusiness in Developing and Emerging Economies, Vol. 6 No. 1, pp. 2-20.

Narine, L., Ganpat, W. and Seepersad, G. (2015), "Demand for organic produce: Trinidadian consumers' willingness to pay for organic tomatoes", Journal of Agribusiness in Developing and Emerging Economies, Vol. 5 No. 1, pp. 76-91. 

$\underset{8,1}{\text { JADEE }}$

Ordinola, M., Devaux, A., Bernet, T., Manrique, K., Lopez, G., Fonseca, C. and Horton, D. (2014), "The PMCA and potato market chain innovation in Peru", Papa Andina Innovation Brief No. 3, International Potato Center, Lima.

Pant, L. and Hambly, H. (2009), "Innovation systems in renewable natural resource management and sustainable agriculture: a literature review", African Journal of Science, Technology, Innovation and Development, Vol. 1 No. 1, pp. 103-135.

Patton, M. (2008), Utilization-Focused Evaluation, Sage, Los Angeles, CA.

Patton, M. (2011), Developmental Evaluation, The Guilford Press, New York, NY.

Pingali, P. (2010), "Global agriculture R\&D and the changing aid architecture", Agricultural Economics, Vol. 41 No. 1, pp. 145-153.

Polar, V., Babini, C. and Flores, P. (2015), Technology for Men and Women: Recommendations to Reinforce Gender Mainstreaming in Agricultural Technology Innovation Processes for Food Security, International Potato Center, La Paz.

Pritchett, L. and Sandefur, J. (2013), "Context matters for size: why external validity claims and development practice don't mix”, Working Paper No. 336, Center for Global Development, London.

Raj, S.P. (2011), "Editorial", Journal of Agribusiness in Developing and Emerging Economies, Vol. 1 No. 1.

Reardon, T. and Timmer, P. (2012), "The economics of the food system revolution", Annual Review of Resource Economics, Vol. 2012 No. 4, pp. 225-264.

Reardon, T., Barrett, C., Berdegué, J. and Swinnen, J. (2009), “Agrifood industry transformation and small farmers in developing countries", World Development, Vol. 37 No. 11, pp. 1717-1727.

Reardon, T., Chen, K., Minten, B. and Adriano, L. (2012), The Quiet Revolution in Staple Food Value Chains: Enter the Dragon, the Elephant, and the Tiger, Asian Development Bank and International Food Policy Research Institute, Mandaluyong City and Washington, DC.

Ricketts, K., Turvey, C. and Gomez, M. (2014), "Value chain approaches to development: smallholder farmer perceptions of risk and benefits across three cocoa chains in Ghana", Journal of Agribusiness in Developing and Emerging Economies, Vol. 4 No. 1, pp. 2-22.

Saenger, C., Torero, M. and Qaim, M. (2014), "Impact of third-party contract enforcement in agricultural markets - a field experiment in Vietnam", American Journal of Agricultural Economics, Vol. 96 No. 4, pp. 1220-1239.

Schut, M., Andersson, J., Dror, I., Kamanda, J., Sartas, M., Mur, R., Kassam, S., Brouwer, H., Stoian, D., Devaux, A., Velasco, C., Gramzow, A., Dubois, T., Flor, R.J., Gummert, M., Buizer, D., McDougall, C., Davis, K., Homann-Kee Tui, S. and Lundy, M. (2017), Innovation Platforms in Agricultural Research for Development: Guidelines for Research, Development, and Funding Agencies on how to Design, Budget, and Implement Successful Innovation Platforms, International Institute of Tropical Agriculture and Wageningen University under the CGIAR Research Program on Roots Tubers and Banana, Kigali.

Shanoyan, A., Ross, R., Gow, H. and Peterson, H. (2014), "Investment responses to third-party market facilitation in Armenia", Journal of Agribusiness in Developing and Emerging Economies, Vol. 4 No. 2, pp. 98-114.

Stoian, D., Donovan, J., Fisk, J. and Muldoon, M. (2012), "Value chain development for rural poverty reduction: a reality check and a warning", Enterprise Development \& Microfinance, Vol. 23 No. 1, pp. 54-69.

Stür, W., Tan Khanh, T. and Duncan, A. (2013), "Transformation of smallholder beef cattle production in Vietnam”, International Journal of Agricultural Sustainability, Vol. 11 No. 4, pp. 363-381.

Swaans, K., Cullen, B., van Rooyen, A., Adekunle, A., Ngwenya, H., Lema, Z. and Nederlof, S. (2013), "Dealing with critical challenges in African innovation platforms: lessons for facilitation", Knowledge Management for Development Journal, Vol. 9 No. 3, pp. 116-135.

Thiele, G., Devaux, A., Reinoso, H., Pico, H., Montesdeoca, F., Pumisacho, M., Andrade-Piedra, J., Velasco, C., Flores, P., Esprella, R., Thomann, A., Manrique, K. and Horton, D. (2011), "Multi-stakeholder platforms for linking small farmers to value chains: evidence from the Andes", International Journal of Agricultural Sustainability, Vol. 9 No. 3, pp. 423-433. 
Tschirley, D., Snyder, J., Dolislager, M., Reardon, T., Haggblade, S., Goeb, J., Traub, L., Ejobi, F. and Meyer, F. (2015), "Africa's unfolding diet transformation: implications for agrifood system employment", Journal of Agribusiness in Developing and Emerging Economies, Vol. 5 No. 2, pp. 102-136.

UNIDO (2011), Pro-Poor Value Chain Development: 25 Guiding Questions for Designing and Implementing Agroindustry Projects, United Nations Industrial Development Organization, Vienna.

Webb, R. (2013), Conexión y Despegue Rural, Instituto del Perú de la Universidad de San Martín de Porres, Lima.

World Bank (2012), Agricultural Innovation Systems: An Investment Sourcebook, World Bank, Washington, DC.

Yusuf, M. and Trondsen, T. (2014), "Competitive forces and innovation strategies: a study of the Indonesian crab industries", Journal of Agribusiness in Developing and Emerging Economies, Vol. 4 No. 1, pp. 78-96.

Zylberberg, E. (2013), "Bloom or bust? A global value chain approach to smallholder flower production in Kenya", Journal of Agribusiness in Developing and Emerging Economies, Vol. 3 No. 1, pp. 4-26.

\begin{abstract}
About the authors
Andre Devaux is the Latin American Regional Program Director for the International Potato Center (CIP), based in Ecuador. Devaux has a PhD Degree in Agriculture Science and has more than 30 years of experience in agricultural research and development in Latin America, Africa, and Asia. His fields of study have included potato production systems, innovation systems, value chain approaches, and food and nutritional security. Prior to working with $\mathrm{CIP}$, he worked with the Food and Agriculture Organization of the United Nations (FAO) and the Swiss Agency for Development and Cooperation (SDC).

Maximo Torero is the Executive Director for Argentina, Bolivia, Chile, Paraguay, Peru and Uruguay at the World Bank. Previously, he was the Director of the Markets, Trade, and Institutions Division at the International Food Policy Research Institute and a Theme Leader for Linking Small Producers to Markets in the CGIAR research program on Policies, Institutions, and Markets. His research interests have included poverty, inequality, and technological change. Torero received his $\mathrm{PhD}$ Degree from the University of California at Los Angeles, and is a Professor on leave at the Universidad del Pacífico (Peru) and an Alexander von Humboldt Fellow at a university (Germany).

Jason Donovan is a Senior Economist, Markets and Value Chains at the International Maize and Wheat Improvement Center (CIMMYT) in Mexico. His main research interests are rural livelihoods, agricultural markets, business development, and seed systems. Prior to joining CIMMYT, he worked at ICRAF in Peru and CATIE in Costa Rica.

Douglas Horton is an Independent Applied Researcher and Program Evaluator based in the USA. He has more than 40 years of experience working on the topics related to agricultural innovation, value-chain development, capacity development, and evaluation of complex systems. From 1975 to 1989, Horton led CIP's Social Science Department (based in Lima, Peru) and from 1990 to 2004, he served as a Senior Officer at the International Service for National Agricultural Research (The Hague, The Netherlands), where he focused on research planning, monitoring, and evaluation. Horton holds a PhD Degree in Economics, with specializations in international development and agriculture. Douglas Horton is the corresponding author and can be contacted at: d.horton@mac.com
\end{abstract}

For instructions on how to order reprints of this article, please visit our website:

www.emeraldgrouppublishing.com/licensing/reprints.htm

Or contact us for further details: permissions@emeraldinsight.com 